Supporting Information

\title{
Enhancing Mechanochemical Activation in the Bulk State by Designing Polymer Architectures
}

Hironori Oka, Keiichi Imato, Tomoya Sato, Tomoyuki Ohishi, Raita Goseki, and Hideyuki Otsuka*

Department of Organic and Polymeric Materials, Tokyo Institute of Technology, 2-12-1 Ookayama, Meguro-ku, Tokyo 152-8550, Japan

Correspondence author: H. Otsuka, E-mail: otsuka@polymer.titech.ac.jp 


\section{Experimental details}

\section{Materials and Instruments}

All solvents and reagents were purchased from Sigma-Aldrich, Wako Pure Chemical Industries, Tokyo Chemical Industry, and Kanto Chemical and used as received, unless otherwise noted. Dihydroxy $\mathrm{DABBF},{ }^{1}$ tetrahydroxy $\mathrm{DABBF}^{2}{ }^{5}$-hexynoyl chloride ${ }^{3}$, and 1,4-bis(phenylethenyl)benzene ${ }^{4}$ (PEB) were synthesized according to previously published methods. Copper (I) bromide $(\mathrm{CuBr})$ was washed with glacial acetic acid and with ethanol and dried at $70{ }^{\circ} \mathrm{C}$. Styrene and 1,3-dibromopropane were distilled under reduced pressure over calcium hydride before used. Prior to use for anionic polymerization, styrene was redistilled over di- $n$-butylmagnesium $\left(\mathrm{Bu}_{2} \mathrm{Mg}\right)(\sim 5 \mathrm{~mol} \%)$ under reduced pressure. ${ }^{1} \mathrm{H}$ NMR spectroscopic measurements were carried out using $300 \mathrm{MHz}$ Bruker spectrometer with tetramethylsilane (TMS) as internal standard in chloroform- $d\left(\mathrm{CDCl}_{3}\right)$. Analytical gel permeation chromatographic (GPC) measurements were carried out at $40{ }^{\circ} \mathrm{C}$ on TOSOH HLC-8320 GPC system equipped with a guard column (TOSOH TSK guard column Super H-L), three columns (TOSOH TSK gel SuperH 6000, 4000, and 2500), a differential refractive index detector, and a UV-vis detector. Tetrahydrofuran (THF) was used as the eluent at a flow rate of $0.6 \mathrm{~mL} / \mathrm{min}$. Polystyrene (PS) standards $\left(M_{\mathrm{n}}=4430-3242000 ; M_{\mathrm{w}} / M_{\mathrm{n}}=1.03-1.08\right)$ were used to calibrate the GPC system. The absolute molecular weight of four-arm star polystyrenes with DABBF was measured on an Asahi Techneion AT-2002 equipped with a Viscotek TDA model 302 triple detector array using THF as a carrier solvent at a flow rate of $1.0 \mathrm{~mL} \mathrm{~min}^{-1}$ at $30{ }^{\circ} \mathrm{C}$. Three PS gel column (pore size (bead size)) were used: $650 \AA(5 \mu \mathrm{m}), 200 \AA(5 \mu \mathrm{m}), 75 \AA(5 \mu \mathrm{m})$. Preparative GPC separating of the target polymers was run on JAI LC-9104 recycling preparative HPLC (JAIGEL $2.5 \mathrm{H} / 3 \mathrm{H}$ column assembly) with chloroform as eluent. 


\section{Grinding tests and electron paramagnetic resonance (EPR) spectroscopy}

Grinding tests were performed on an auto-grinding machine, STM-D from ASONE. The mechanical energy was controlled by the rotational speed of the mortal. A powdered sample $(100 \mathrm{mg}$ ) was placed in the mortar and ground for $10 \mathrm{~min}$ at $100 \mathrm{rpm}$. The ground sample was transferred into an EPR glass capillary, and the capillary was sealed after being degassed. EPR measurements were carried out on a JEOL JES-X320 X-band EPR spectrometer equipped with a JEOL DVT temperature controller. The spectra of ground samples were measured using a microwave power of $0.1 \mathrm{~mW}$ and a field modulation of $0.1 \mathrm{mT}$ with a time constant of $0.03 \mathrm{~s}$ and a sweep rate of $0.25 \mathrm{mT} / \mathrm{s}$ at $25{ }^{\circ} \mathrm{C}$. The concentration of the radicals formed from the cleavage of DABBF was determined by comparing the area of the observed integral spectrum with a $0.01 \mathrm{mM}$ solution of 4-hydroxy-2,2,6,6-tetramethylpiperidin-1-oxyl (TEMPOL) in benzene under the same experimental conditions. The $g$ value was calculated according to the following equation: $g=h v / \beta H$ where $h$ is the Planck constant, $v$ is the microwave frequency, $\beta$ is the Bohr magneton, and $H$ is the magnetic field.

\section{Variable-Temperature EPR spectroscopy}

EPR measurements were carried out on a JEOL JES-X320 X-band EPR spectrometer equipped with a JEOL DVT temperature controller. The measured powdered samples were filled to $5 \mathrm{~mm}$ glass capillaries, and the capillaries were sealed after being degassed. Spectra were measured using microwave power of $0.1 \mathrm{~mW}$ and a field modulation of $0.1 \mathrm{mT}$ with a time constant of $0.03 \mathrm{~s}$ and a sweep rate of $0.25 \mathrm{mTs}^{-1}$. The concentration of the radicals formed from cleaved DABBF was determined by comparing the area of the observed integral spectrum with that of $0.01 \mathrm{mM}$ TEMPOL in benzene under the same experimental condition; the $\mathrm{Mn}^{2+}$ signal was used as an auxiliary standard. 


\section{Synthesis of diarylbibenzofuranone-dialkyne derivative}

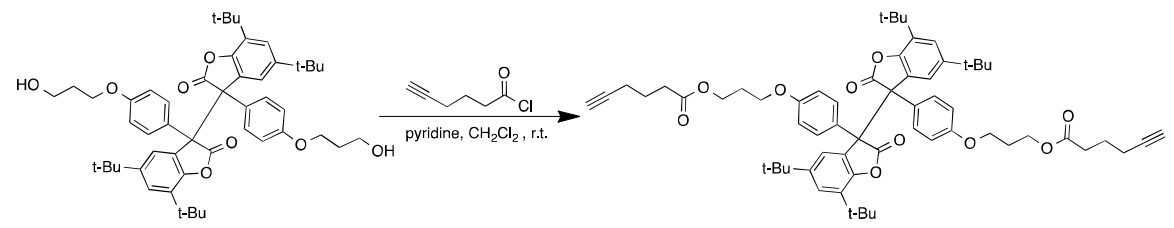

Dihydroxy-DABBF (2.0 g, $2.5 \mathrm{mmol})$ was added to a flask. The flask was degassed and back-filled with nitrogen three times. $\mathrm{CH}_{2} \mathrm{Cl}_{2}(15 \mathrm{~mL})$ and pyridine $(2.5 \mathrm{~mL}, 30 \mathrm{mmol})$ were added to the flask under nitrogen flow. 5-hexynoyl chloride $(1.2 \mathrm{~mL}, 10 \mathrm{mmol})$ was then added dropwise to the flask at $0{ }^{\circ} \mathrm{C}$. The mixture was stirred at $0{ }^{\circ} \mathrm{C}$ for $1 \mathrm{~h}$ and at room temperature for $18.5 \mathrm{~h}$. To stop the reaction, deionized water was added to the flask. The reaction mixture was extracted with $\mathrm{CH}_{2} \mathrm{Cl}_{2}$ three times. The organic layer was washed with water twice and brine once, dried over anhydrous $\mathrm{MgSO}_{4}$, and evaporated. The crude product was purified by slica gel column chromatography eluting with ethyl acetate/n-hexane $(1 / 2)$. The desired compound was dried under vacuum $(2.4 \mathrm{~g}, 96 \%) .{ }^{1} \mathrm{H}$ NMR spectrum of DABBF-dialkyne derivative was shown in Figure S1.

${ }^{1} \mathrm{H}$ NMR (300 MHz, $\left.\mathrm{CDCl}_{3}\right): \delta / \mathrm{ppm} 1.16\left(\mathrm{br}, 18 \mathrm{H}, \mathrm{CH}_{3}\right), 1.31\left(\mathrm{br}, 18 \mathrm{H}, \mathrm{CH}_{3}\right), 1.85(\mathrm{~m}, 4 \mathrm{H}$, $\mathrm{CH}_{2}$ ), 1.96 (t, 2H, CH), $2.13\left(\mathrm{~m}, 4 \mathrm{H}, \mathrm{CH}_{2}\right.$ ), 2.26 (m, 4H, $\mathrm{CH}_{2}$ ), 2.47 (t, J= $7.4 \mathrm{~Hz}, 4 \mathrm{H}, \mathrm{CH}_{2}$ ), $4.07\left(\mathrm{~m}, 4 \mathrm{H}, \mathrm{CH}_{2}\right), 4.28\left(\mathrm{t}, 4 \mathrm{H}, \mathrm{CH}_{2}\right), 6.82(\mathrm{~d}, 6 \mathrm{H}$, aromatic proton), 7.27 (br, 6H, aromatic proton). ${ }^{13} \mathrm{C}$ NMR: (75 MHz, $\mathrm{CDCl}_{3}$ ): $\delta / \mathrm{ppm} \mathrm{17.72,} \mathrm{23.44,} \mathrm{29.57,} \mathrm{31.44,} \mathrm{34.26,} \mathrm{34.61,} \mathrm{61.11,}$ $64.20,69.17,83.08,113.03,123.88,132.19,133.39,145.58,149.02,158.73,172.94$.

\section{Synthesis of diarylbibenzofuranone-tetraalkyne derivative}

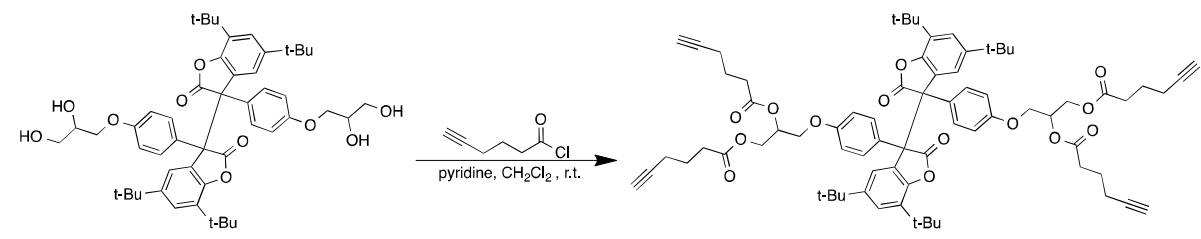

Tetrahydroxy-DABBF (2.0 g, $2.4 \mathrm{mmol})$ was added to a flask. The flask was degassed and back-filled with nitrogen three times. $\mathrm{CH}_{2} \mathrm{Cl}_{2}(20 \mathrm{~mL})$ and pyridine $(3.1 \mathrm{~mL}, 39$ mmol) were added to the flask under nitrogen flow. 5-hexynoyl chloride $(2.3 \mathrm{~mL}, 19 \mathrm{mmol})$ was 
then added dropwise to the flask at $0{ }^{\circ} \mathrm{C}$. The mixture was stirred at $0{ }^{\circ} \mathrm{C}$ for $1 \mathrm{~h}$ and at room temperature for $27.5 \mathrm{~h}$. To stop the reaction, deionized water was added to the flask. The reaction mixture was extracted with $\mathrm{CH}_{2} \mathrm{Cl}_{2}$ three times. The organic layer was washed with water twice and brine once, dried over anhydrous $\mathrm{MgSO}_{4}$, and evaporated. The crude product was purified by silica gel column chromatography eluting with ethyl acetate/n-hexane (1/4). The desired compound was dried under vacuum (2.5 g, 85\%). ${ }^{1} \mathrm{H}$ NMR spectrum of DABBF-tetraalkyne derivative was shown in Figure S2.

${ }^{1} \mathrm{H}$ NMR (300 MHz, $\left.\mathrm{CDCl}_{3}\right): \delta / \mathrm{ppm} 1.17\left(\mathrm{br}, 18 \mathrm{H}, \mathrm{CH}_{3}\right), 1.31\left(\mathrm{br}, 18 \mathrm{H}, \mathrm{CH}_{3}\right), 1.84(\mathrm{~m}, 8 \mathrm{H}$, $\left.\mathrm{CH}_{2}\right), 1.97(\mathrm{~m}, 4 \mathrm{H}, \mathrm{CH}), 2.27\left(\mathrm{~m}, 8 \mathrm{H}, \mathrm{CH}_{2}\right), 2.48\left(\mathrm{~m}, 8 \mathrm{H}, \mathrm{CH}_{2}\right), 4.13\left(\mathrm{~m}, 4 \mathrm{H}, \mathrm{CH}_{2}\right), 4.30(\mathrm{~m}, 2 \mathrm{H}$, $\left.\mathrm{CH}_{2}\right), 4.47\left(\mathrm{~m}, 2 \mathrm{H}, \mathrm{CH}_{2}\right) 5.41(\mathrm{~m}, 3 \mathrm{H}, \mathrm{CH}) 6.82(\mathrm{~d}, 6 \mathrm{H}$, aromatic proton), $7.28(\mathrm{br}, 6 \mathrm{H}$, aromatic proton). ${ }^{13} \mathrm{C}$ NMR: (75 MHz, $\left.\mathrm{CDCl}_{3}\right): \delta / \mathrm{ppm} 17.63,17.65,23.34,23.39,29.55,31.43,32.50$, $32.70,34.61,62.32,69.28,69.41,82.97,113.13,132.24,133.47,149.00,158.20,158.21$, $172.21,172.54$

\section{Synthesis of bromine-terminated polystyrene ${ }^{4}$}

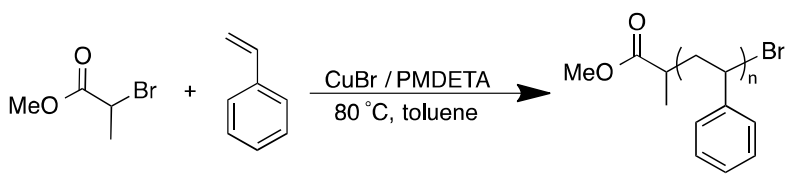

In a typical run, styrene $(9.0 \mathrm{~mL}, 78 \mathrm{mmol})$, toluene $(6.0 \mathrm{~mL})$, $N, N, N^{\prime}, N^{\prime}, N^{\prime \prime}$-pentamethyldiethylenetriamine (PMDETA) $(163 \mu \mathrm{L}, 0.78 \mathrm{mmol})$, and methyl 2-bromopropionate ( $87 \mu \mathrm{L}, 0.78 \mathrm{mmol}$ ) were added to a schlenk flask. The schlenk flask was degassed by means of three freeze-pump-thaw cycles and filled with nitrogen. The schlenk flask was carefully opened and $\mathrm{CuBr}(112 \mathrm{mg}, 0.78 \mathrm{mmol})$ was quickly added, after which the schlenk flask was degassed again with three freeze-pump-thaw cycles, filled with nitrogen, sealed, and heated at $80^{\circ} \mathrm{C}$ for $4.5 \mathrm{~h}$. The reaction was stopped by opening the flask and exposing the catalyst to air. The mixture was diluted in tetrahydrofuran (THF) and passed through a neutral alumina column in order to remove the copper catalyst. The mixture was concentrated by rotary evaporation and subsequently precipitated in methanol. The precipitated bromine-terminated polystyrene was filtered and dried under vacuum at $40{ }^{\circ} \mathrm{C}$ to afford a white powder ( $3.0 \mathrm{~g}, 77 \%$ yield). The $M_{\mathrm{n}}$ and $M_{\mathrm{w}} / M_{\mathrm{n}}$ values were determined by analytical GPC with polystyrene standards. $M_{\mathrm{n}}=4900 \mathrm{~g} \mathrm{~mol}^{-1}, M_{\mathrm{w}} / M_{\mathrm{n}}=1.20$. 


\section{Synthesis of azide-terminated polystyren $\mathrm{e}^{5}$}

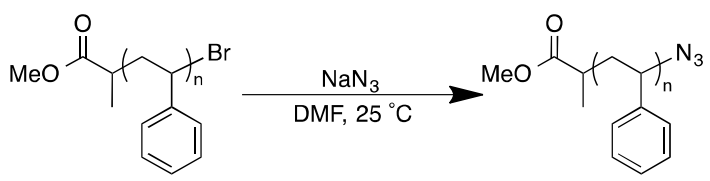

In a typical run, bromine-terminated polystyrene $\left(2.5 \mathrm{~g}, 0.50 \mathrm{mmol}, 4900 \mathrm{~g} \mathrm{~mol}^{-1}\right)$, sodium azide ( $332 \mathrm{mg}, 5.0 \mathrm{mmol}$ ), and DMF $(25 \mathrm{~mL})$ were added to a flask. The reaction mixture was stirred at $25^{\circ} \mathrm{C}$ for $24 \mathrm{~h}$. Then, the reaction mixture was precipitated in methanol, filtered, and dried under vacuum at $40{ }^{\circ} \mathrm{C}$ to afford a white azide-terminated polystyrene $(2.5 \mathrm{~g}$, $97 \%$ yield). The substitution was verified by the signal shift of the methine proton neighboring the bromine in ${ }^{1} \mathrm{H}$ NMR spectra of the polymers before and after the reaction as shown in Figure S3.

\section{Synthesis of in-chain azide-functionalized polystyrene}

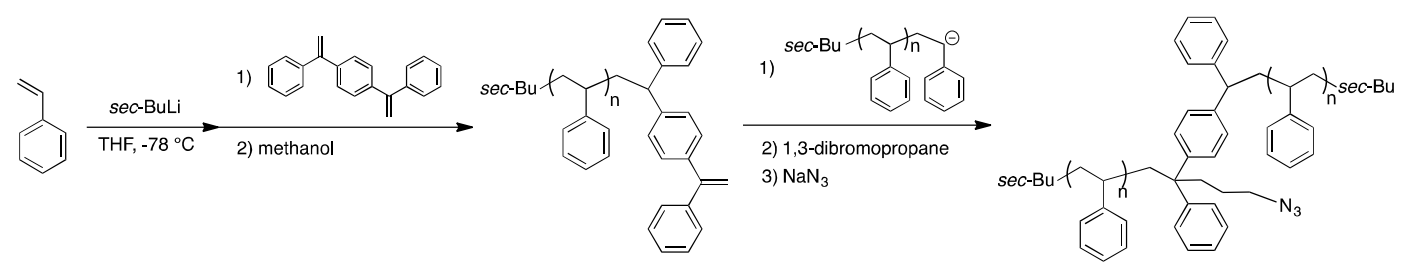

THF (40 mL) was transferred to a glass reactor equipped with stir bar and cooled to $-78^{\circ} \mathrm{C}$. After $5 \mathrm{~min}, \mathrm{sec}-\mathrm{BuLi}$ was added until the color changed to slightly yellow. The reactor was removed from the cooling-bath and allowed to reach room temperature, upon which the solution became colorless. The reactor was cooled back to $-78{ }^{\circ} \mathrm{C}$, and $1.07 \mathrm{M}$ sec-BuLi solution in hexane/cyclohexane $(0.36 \mathrm{mmol})$ was added. After $5 \mathrm{~min}$, styrene $(4.5 \mathrm{~mL}, 39.2 \mathrm{mmol})$ was added to the reactor with vigorous stirring. After $10 \mathrm{~min}$, PEB that had been dried under reduced pressure for several hours $(0.13 \mathrm{~g}, 0.47 \mathrm{mmol})$ was dissolved in THF $(5.0 \mathrm{~mL})$ and transferred from the reservoir to the polymerization flask via syringe with vigorous stirring. The solution color changed deep blue. After $1 \mathrm{~h}$ at $-78{ }^{\circ} \mathrm{C}$, excess of methanol was added to the reactor to obtain the proton-terminated polymer. It was purified by reprecipitation twice from THF into 
methanol and freeze-drying from its absolute benzene solution (3.91 g, 96\%). ${ }^{1} \mathrm{H}$ NMR (300 $\mathrm{MHz}, \mathrm{CDCl}_{3}$ ): $\delta / \mathrm{ppm}$ 0.74-0.87 (br, isobutyl), 1.18-2.16 (br, PS backbone), 5.40 (s, $\mathrm{CH}_{2}=\mathrm{C}$ ), 6.22-7.23 (br, PS). $M_{\mathrm{n}}=11200 \mathrm{~g} \mathrm{~mol}^{-1}$

A THF solution $(20.0 \mathrm{~mL})$ of $\omega$-chain-ended DPE-functionalized PS (3.80 g, $0.34 \mathrm{mmol}, M_{\mathrm{n}}$ $=11200)$ pre-cooled at $-78{ }^{\circ} \mathrm{C}$, was added to prior prepared the living polystyrene $(0.40 \mathrm{mmol}$, $\left.M_{\mathrm{n}}=9600 \mathrm{~g} \mathrm{~mol}^{-1}\right)$ at $-78{ }^{\circ} \mathrm{C}$ for $10 \mathrm{~min}$. The reaction mixture was allowed to stand at $-78{ }^{\circ} \mathrm{C}$ for $3 \mathrm{~h}$. Then, the resulting in-chain anion reacted with 1,3-dibromopropane ( $0.83 \mathrm{~g}, 3.40 \mathrm{mmol})$ in THF $(3.0 \mathrm{~mL})$ at $-78{ }^{\circ} \mathrm{C}$ for $3 \mathrm{~h}$. The reaction mixture was terminated by a small amount of degassed methanol and poured into a large amount of methanol to precipitate the polymer. The objective in-chain bromo-functionalized polystyrenes was isolated by fractional precipitation using cyclohexane and hexane mixtures in $83 \%$ yield. ${ }^{1} \mathrm{H}$ NMR $\left(300 \mathrm{MHz}, \mathrm{CDCl}_{3}\right): \delta / \mathrm{ppm}$ 0.74-0.87 (br, isobutyl), 1.18-2.16 (br, PS backbone), 3.22 (br, $\mathrm{Br}_{-} \mathrm{CH}_{2}-$ ), 6.22-7.23 (br, PS). $M_{\mathrm{n}}$ $=20200 \mathrm{~g} \mathrm{~mol}^{-1}$.

The bromo function of polymer $(6.00 \mathrm{~g}, 0.29 \mathrm{mmol})$ was converted to the azide group by reacted with sodium azide $(0.18 \mathrm{~g}, 2.90 \mathrm{mmol})$ in the same manner as mentioned above $(5.72 \mathrm{~g}$, 97\%). ${ }^{1} \mathrm{H}$ NMR (300 MHz, $\mathrm{CDCl}_{3}$ ): $\delta / \mathrm{ppm}$ 0.74-0.87 (br, isobutyl), 1.18-2.16 (br, PS backbone), $2.86\left(\mathrm{br}, \mathrm{N}_{3}-\mathrm{CH}_{2}-\right)$, 6.22-7.23 (br, PS).

\section{Synthesis of linear polystyrene with diarylbibenzofuranone functionality in the center of} polymer chain ${ }^{5}$

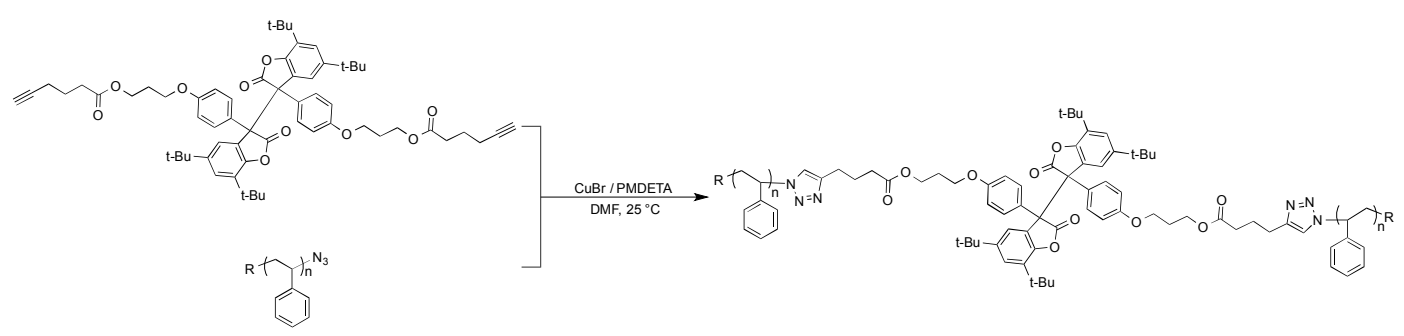

In a typical run, azide-terminated polystyrene $\left(1.3 \mathrm{~g}, 0.26 \mathrm{mmol}, 4900 \mathrm{~g} \mathrm{~mol}^{-1}\right)$, DABBF-dialkyne derivative (127 mg, $0.13 \mathrm{mmol})$, DMF (13 mL), and PMDETA (54 $\mu \mathrm{L}, 0.26$ mmol) were added to a flask. The flask was capped with a septum and the mixture was bubbled with nitrogen for $20 \mathrm{~min}$. The flask was carefully opened and $\mathrm{CuBr}(37 \mathrm{mg}, 0.26 \mathrm{mmol})$ was quickly added, after which the flask was filled with nitrogen and sealed. The mixture was stirred 
at $25^{\circ} \mathrm{C}$ for $24 \mathrm{~h}$. The reaction was stopped by opening the flask and exposing the catalyst to air. The mixture was diluted in THF, passed through a neutral alumina column in order to remove the copper catalyst, concentrated, and subsequently precipitated in methanol. The precipitated polymer was filtered and dried under vacuum at $40{ }^{\circ} \mathrm{C}$. The target linear polymer was isolated by preparative GPC, fractional precipitation using cyclohexane/hexane, and precipitation in methanol, and dried under vacuum at $40{ }^{\circ} \mathrm{C}$ to afford a white powder $(0.61 \mathrm{~g}, 50 \%$ yield $) .{ }^{1} \mathrm{H}$ NMR spectrum of the linear polymer was shown in Figure S4. The $M_{\mathrm{n}}$ and $M_{\mathrm{w}} / M_{\mathrm{n}}$ values were determined by analytical GPC with polystyrene standards (Figure S5). $M_{\mathrm{n}}=13100 \mathrm{gmol}^{-1}$, $M_{\mathrm{w}} / M_{\mathrm{n}}=1.05$.

${ }^{1} \mathrm{H}$ NMR (300 MHz, $\mathrm{CDCl}_{3}$ ): $\delta / \mathrm{ppm} 0.81-0.94$ (br, $-\mathrm{CHCH}_{3}$ ), 1.13 (br, $\left.{ }^{t} \mathrm{Bu}\right), 1.19-2.15$ (br, PS backbone), 2.25 (br, $\mathrm{CH}_{2}$ ), 2.59 (br, $\mathrm{CH}_{2}$ ), 3.42 (br, $-\mathrm{OCH}_{3}$ ), 4.02 (br, $\left.\mathrm{CH}_{2}\right), 4.22\left(\mathrm{br}, \mathrm{CH}_{2}\right), 5.04$ (br, -CHPh), 6.17-7.23 (br, PS).

\section{Synthesis of four-arm star polystyrene with diarylbibenzofuranone functionality at the} core

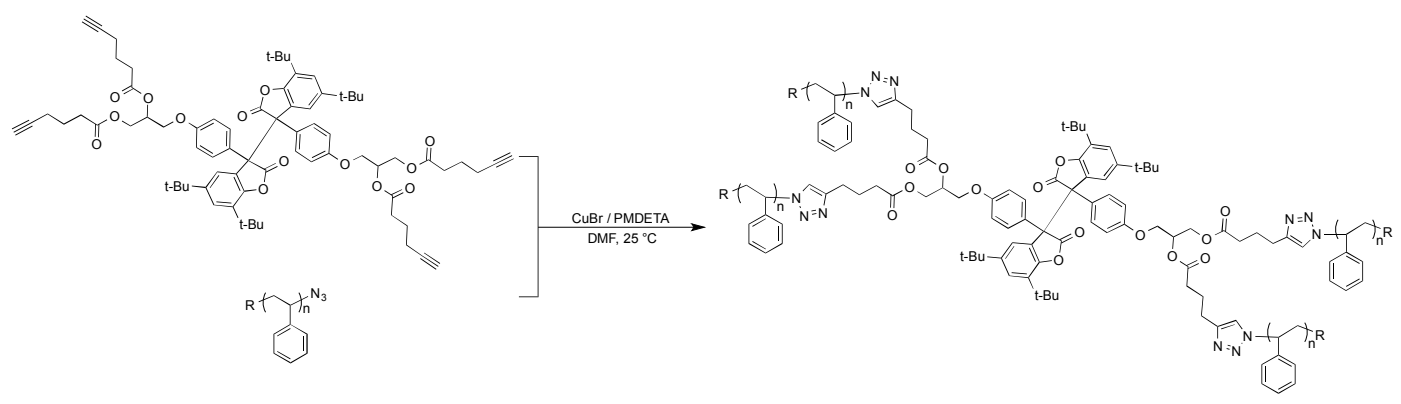

Azide-terminated polystyrene $\left(2.0 \mathrm{~g}, \quad 0.17 \mathrm{mmol}, \quad 11600 \mathrm{~g} \quad \mathrm{~mol}^{-1}\right)$, DABBF-tetraalkyne derivative (41 mg, $0.034 \mathrm{mmol}$ ), DMF (15 mL), and PMDETA (36 $\mu \mathrm{L}$, $0.17 \mathrm{mmol}$ ) were added to a flask. The flask was capped with a septum and the mixture was bubbled with nitrogen for $20 \mathrm{~min}$. The flask was carefully opened and $\mathrm{CuBr}$ (25 mg, 0.17 mmol) was quickly added, after which the flask was filled with nitrogen and sealed. The mixture was stirred at $25^{\circ} \mathrm{C}$ for $24 \mathrm{~h}$. The reaction was stopped by opening the flask and exposing the catalyst to air. The mixture was diluted in THF, passed through a neutral alumina column in order to remove the copper catalyst, concentrated, and subsequently precipitated in methanol. The precipitated polymer was filtered and dried under vacuum at $40{ }^{\circ} \mathrm{C}$. The target star polymer was isolated by fractional precipitation using cyclohexane/hexane and then 
precipitation in methanol, and dried under vacuum at $40{ }^{\circ} \mathrm{C}$ to afford a white powder $(0.68 \mathrm{~g}$, $45 \%$ yield). The $M_{\mathrm{n}}$ and $M_{\mathrm{w}} / M_{\mathrm{n}}$ values were estimated by analytical GPC with polystyrene standards. $M_{\mathrm{n}}=38600 \mathrm{~g} \mathrm{~mol}^{-1}, M_{\mathrm{w}} / M_{\mathrm{n}}=1.05$. The absolute $M_{\mathrm{n}}$ value was estimated by GPC equipped with RI, viscometer, and right angle laser light scattering (RALLS) detection. $M_{\mathrm{n}}$ $(\mathrm{GPC}-\mathrm{RALLS})=44200 \mathrm{~g} \mathrm{~mol}^{-1}$.

${ }^{1} \mathrm{H}$ NMR (300 MHz, $\mathrm{CDCl}_{3}$ ): $\delta / \mathrm{ppm}$ 0.80-0.94 (br, $-\mathrm{CHCH}_{3}$ ), 1.14 (br, $\left.{ }^{t} \mathrm{Bu}\right), 1.19-2.16$ (br, PS backbone), 2.26 (br, $\mathrm{CH}_{2}$ ), 2.58 (br, $\mathrm{CH}_{2}$ ), 3.41 (br, $-\mathrm{OCH}_{3}$ ), 4.04 (br, $\left.\mathrm{CH}_{2}\right), 4.23$ (br, $\mathrm{CH}_{2}$ ), 5.05 (br, -CHPh), 6.16-7.25 (br, PS).

\section{Synthesis of eight-arm star polystyrene with diarylbibenzofuranone functionality at the} core

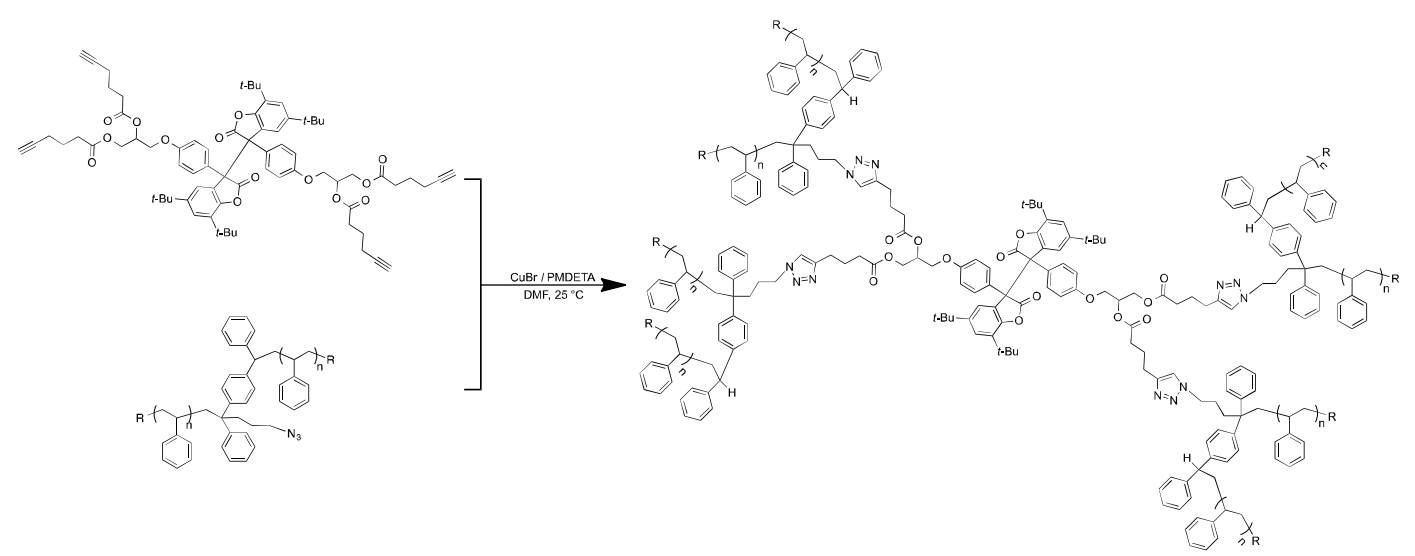

Eight-arm star polystyrene with diarylbibenzofuranone functionality at the core was synthesized by click reaction as similar manner using in-chain azide-functionalized polystyrene (5.0 g, $0.24 \mathrm{mmol}$ ), DABBF-tetraalkyne derivative (64 mg, $0.054 \mathrm{mmol}$ ), DMF (45 mL), CuBr (34.4 mg, $0.24 \mathrm{mmol}$ ), and PMDETA ( $51 \mu \mathrm{L}, 0.24 \mathrm{mmol})$. The target star polymer was isolated by fractional precipitation ( $1.98 \mathrm{~g}, 44 \%$ yield). The absolute $M_{\mathrm{n}}$ value was estimated by GPC equipped with RI, viscometer, and right angle laser light scattering (RALLS) detection. $M_{\mathrm{n}}$ $(\mathrm{GPC}-\mathrm{RALLS})=81600 \mathrm{~g} \mathrm{~mol}^{-1}$.

${ }^{1} \mathrm{H}$ NMR (300 MHz, $\mathrm{CDCl}_{3}$ ): $\delta / \mathrm{ppm}$ 0.71-0.87 (br, isobutyl), 0.88-0.94 (br, - $\mathrm{CHCH}_{3}$ ), 1.14 (br, ${ }^{t} \mathrm{Bu}$ ), 1.18-2.42 (br, PS backbone and $\left.\mathrm{CH}_{2}\right), 2.62\left(\mathrm{br}, \mathrm{CH}_{2}\right), 4.12\left(\mathrm{br}, \mathrm{CH}_{2}\right), 4.25\left(\mathrm{br}, \mathrm{CH}_{2}\right)$, 6.16-7.25 (br, PS). 


\section{Selective Scission of DABBF units in the center of polymer structure}
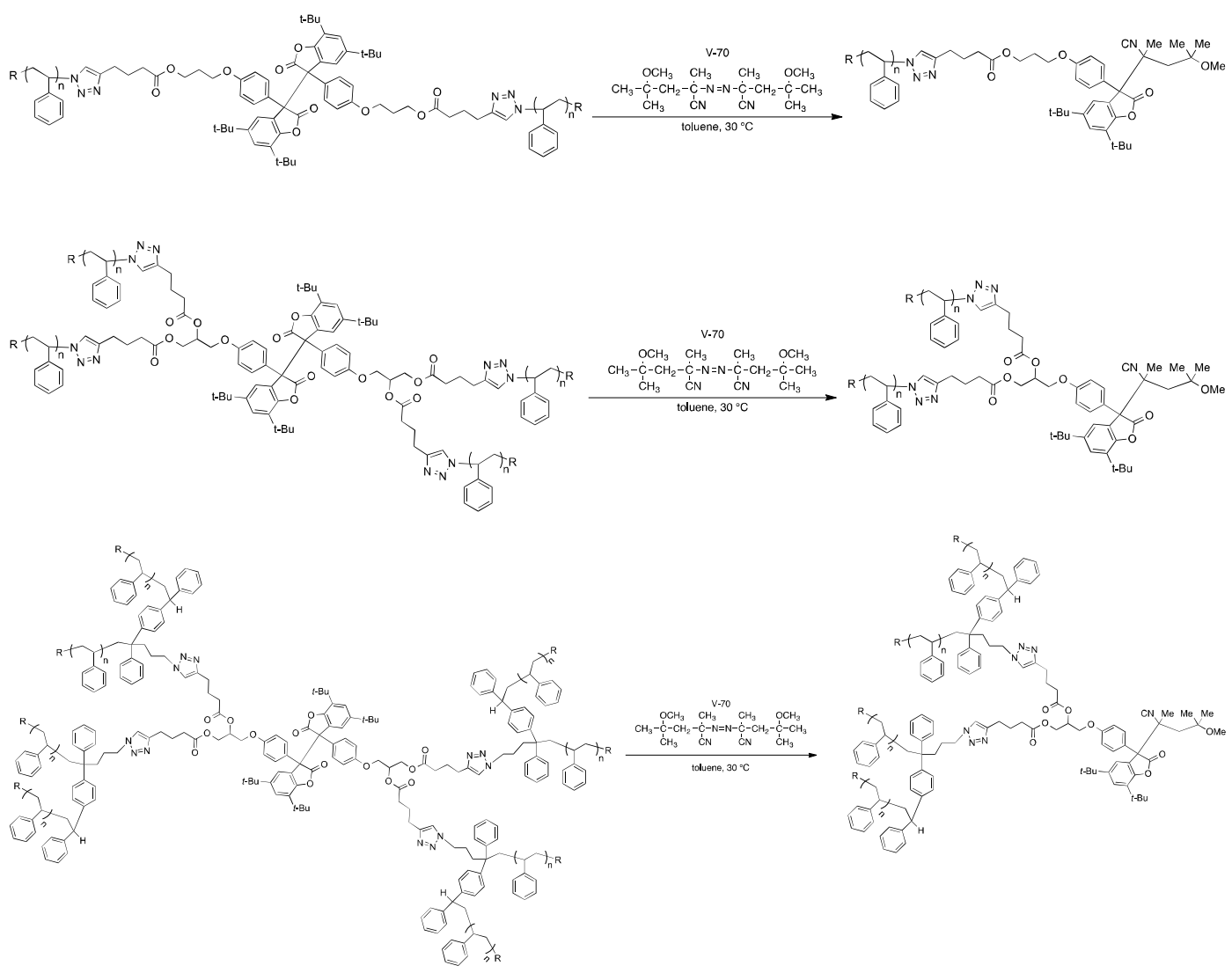

Linear polystyrene with DABBF in the center of polymer chain $(50 \mathrm{mg}, 3.8 \mu \mathrm{mol}$, $\left.11600 \mathrm{~g} \mathrm{~mol}^{-1}\right)$ and toluene $(3.8 \mathrm{~mL})$ were added to a test tube. The reaction vessel was capped with a septum and the mixture was bubbled with nitrogen for $20 \mathrm{~min}$. 2,2'-Azobis(4-methoxy-2,4-dimethylvaleronitrile) (V-70) (24 mg, $0.077 \mathrm{mmol}$ ) was added to the reaction vessel and the mixture was bubbled with nitrogen for $20 \mathrm{~min}$. The reaction was carried out at $30{ }^{\circ} \mathrm{C}$ and traced by GPC. After $24 \mathrm{~h}$, the reaction mixture was precipitated in methanol and the precipitated polymer was filtered and dried under vacuum ( $46 \mathrm{mg}, 92 \%$ yield). The $M_{\mathrm{n}}$ and $M_{\mathrm{w}} / M_{\mathrm{n}}$ values were estimated by analytical GPC with polystyrene standards (Figure S6). $M_{\mathrm{n}}=6700 \mathrm{~g} \mathrm{~mol}^{-1}, M_{\mathrm{w}} / M_{\mathrm{n}}=1.06$. The selective scission reaction condition of DABBF units in the star polymers $\left(M_{\mathrm{nGPC}}=38600,52100 \mathrm{~g} \mathrm{~mol}^{-1}\right)$ were similar to that mentioned above (over $90 \%$ yield). The $M_{\mathrm{n}}$ and $M_{\mathrm{w}} / M_{\mathrm{n}}$ values were estimated by analytical GPC with polystyrene standards (Figure S7,8). Four-arm star polystyrene: $M_{\mathrm{n}}=22000 \mathrm{~g} \mathrm{~mol}^{-1}, M_{\mathrm{w}} / M_{\mathrm{n}}=$ 1.06. Eight-arm star polystyrene: $M_{\mathrm{n}}=34600 \mathrm{~g} \mathrm{~mol}^{-1}, M_{\mathrm{w}} / M_{\mathrm{n}}=1.04$. 


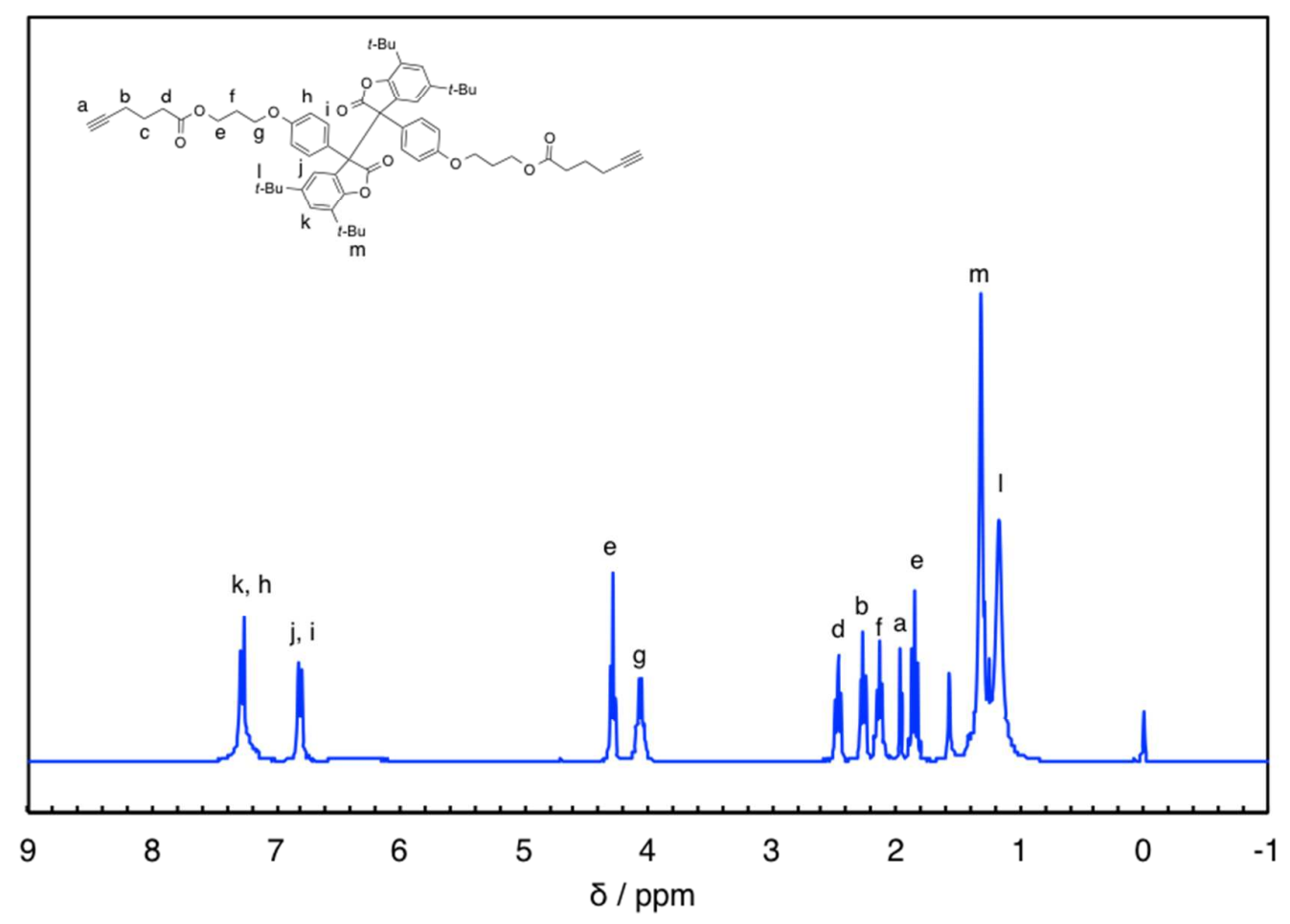

Figure S1. ${ }^{1} \mathrm{H}$ NMR spectrum of DABBF-dialkyne derivative.

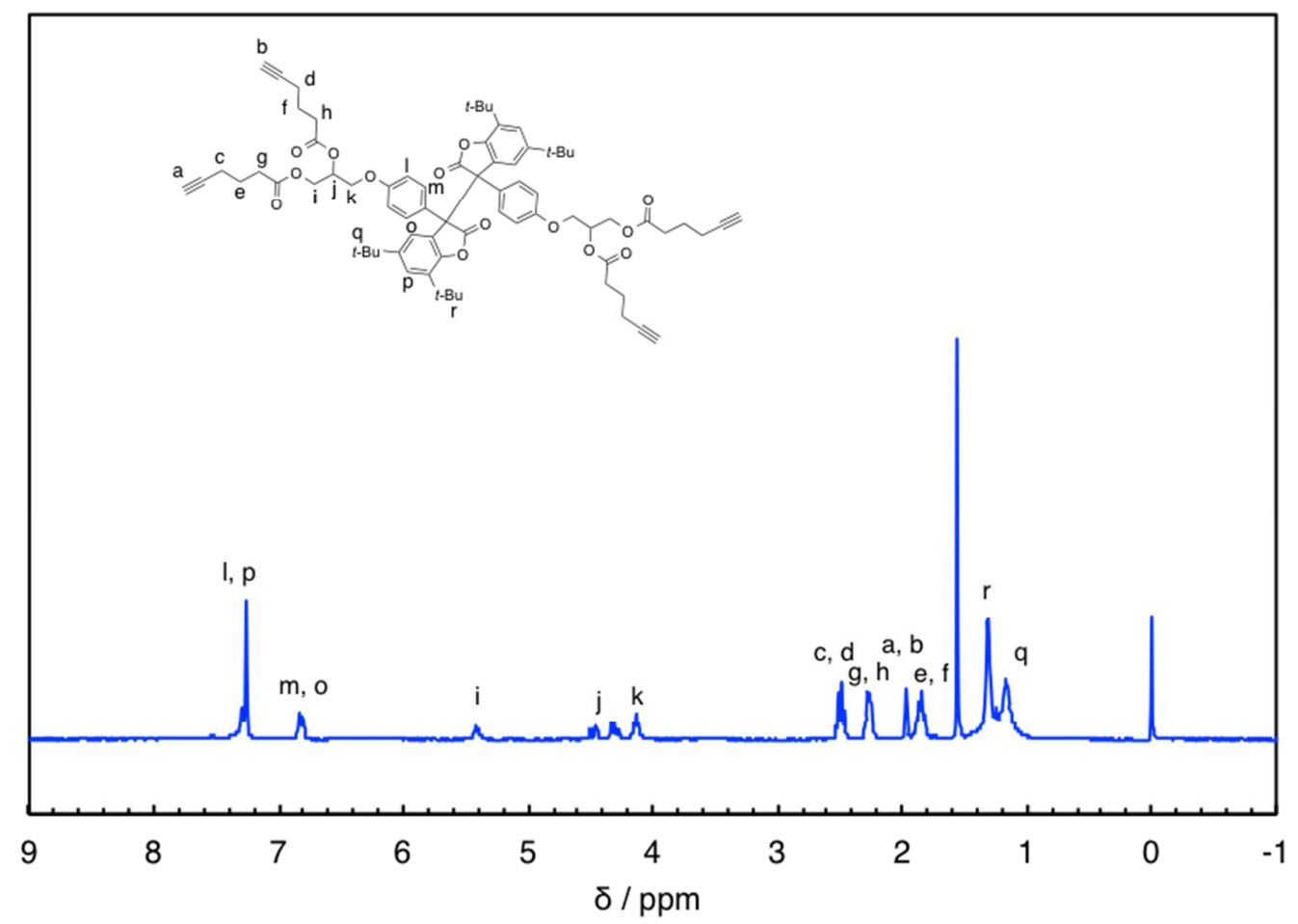

Figure S2. ${ }^{1} \mathrm{H}$ NMR spectrum of DABBF-tetraalkyne derivative. 


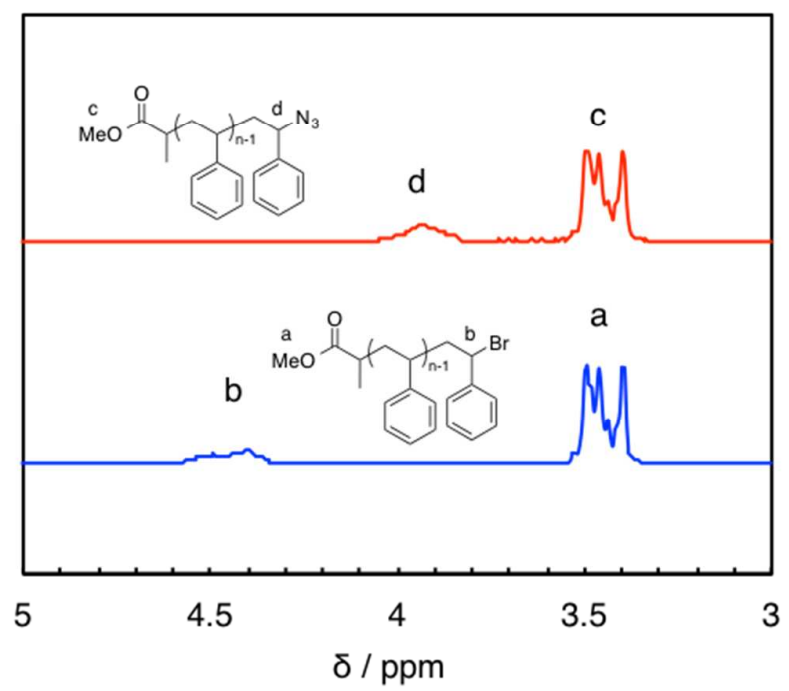

Figure S3. ${ }^{1} \mathrm{H}$ NMR spectra of bromine-terminated polystyrene $\left(M_{\mathrm{n}}=4900\right)$ (blue) and azide-terminated polystyrene $\left(M_{\mathrm{n}}=4900\right)(\mathrm{red})$ in the chemical shift range from 3.0 to $6.0 \mathrm{ppm}$. 
(a)

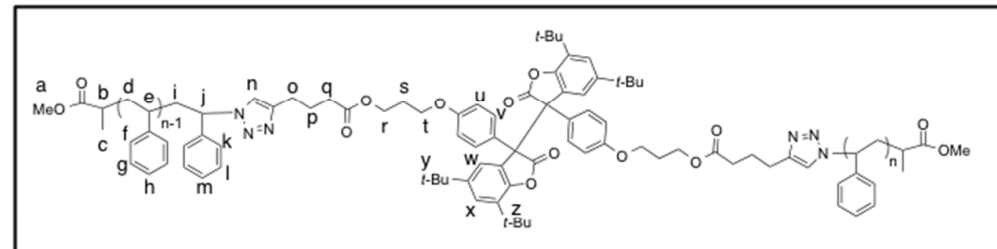

f, g, h, k, I, m, n, u, v, w, x

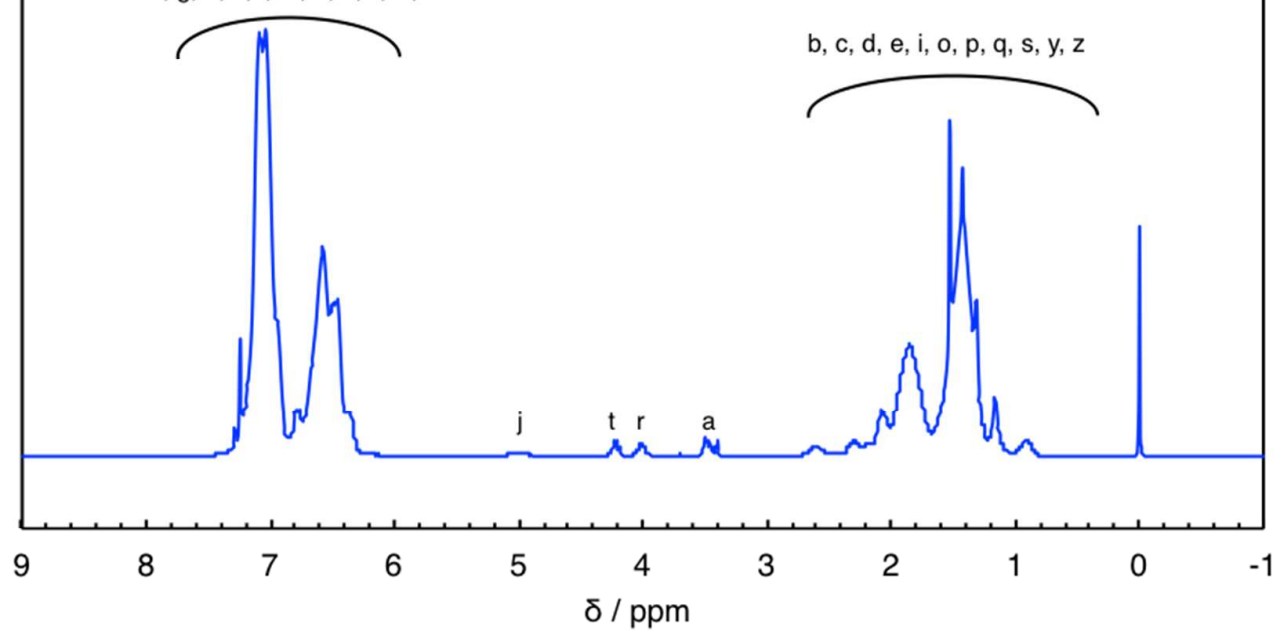

(b)

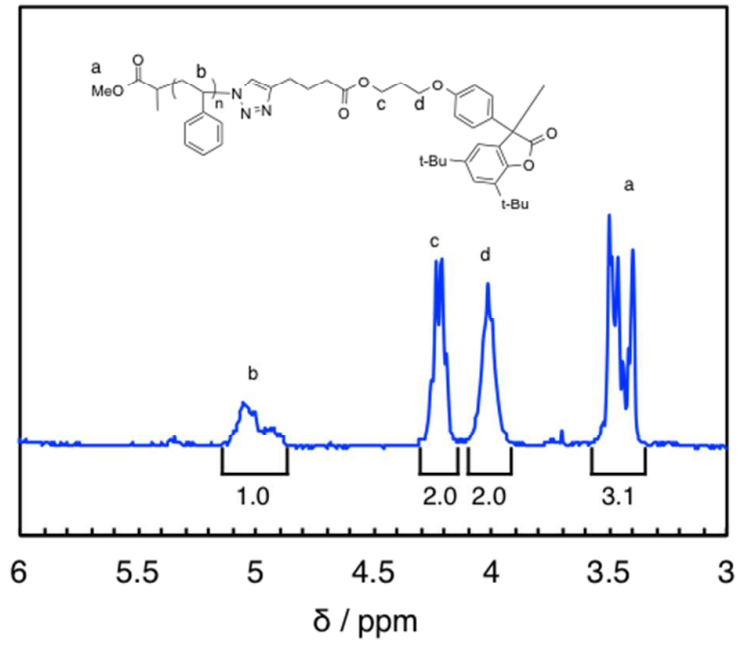

Figure S4. (a) ${ }^{1} \mathrm{H}$ NMR spectrum of linear polystyrene with DABBF in the center of polymer chain $\left(M_{\mathrm{n}}=13100\right)$, and $(\mathrm{b})$ the extended figure in the chemical shift range from 3.0 to $6.0 \mathrm{ppm}$. 


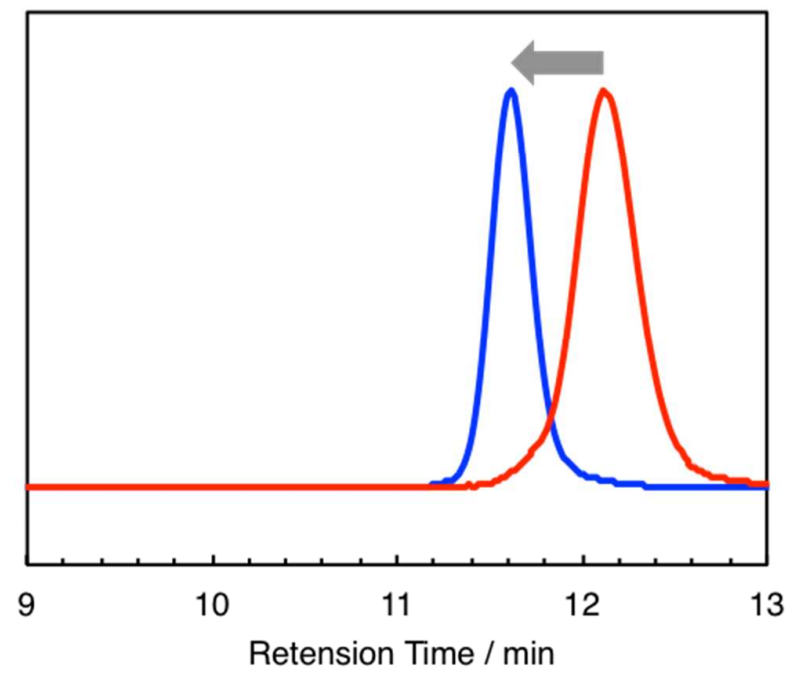

Figure S5. GPC profiles of azide-terminated polystyrene $\left(M_{\mathrm{n}}=4900\right)$ (red) and DABBF mid-functionalized linear polystyrene $\left(M_{\mathrm{n}}=13100\right)$ (blue). 


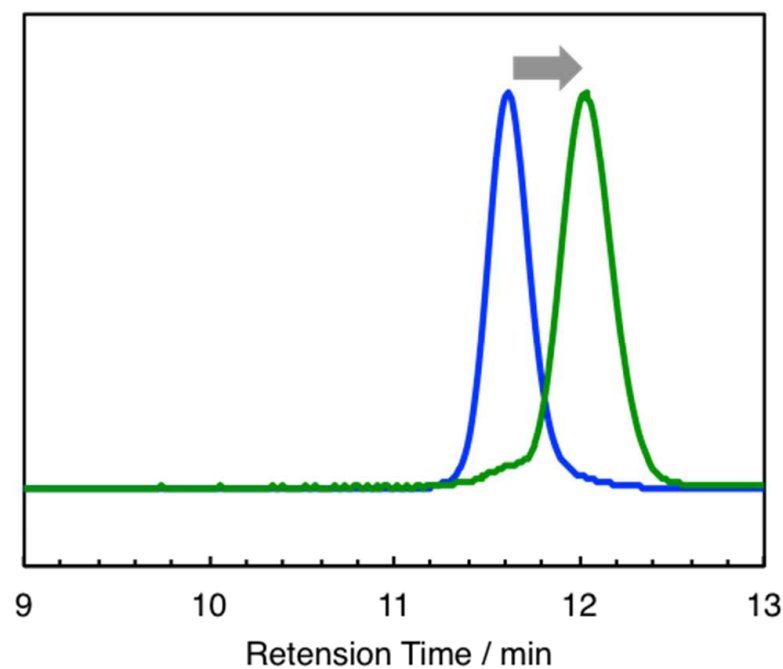

Figure S6. GPC profiles of linear polystyrene with DABBF in the center of polymer chain $\left(M_{\mathrm{n}}\right.$ $=13100)$ before (blue) and after (green) treatment with a radical generator $(\mathrm{V}-70)\left(M_{\mathrm{n}}=6700\right)$. 


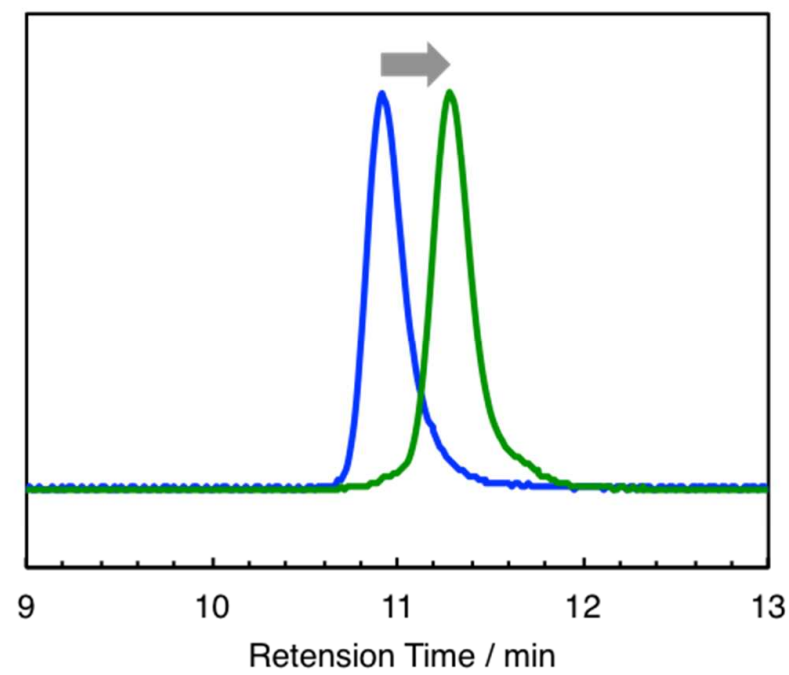

Figure S7. GPC profiles of star polystyrene with DABBF in the core of polymer structure $\left(M_{\mathrm{n}}=\right.$ $38600)$ before (blue) and after (green) treatment with a radical generator (V-70) $\left(M_{\mathrm{n}}=22000\right)$. 


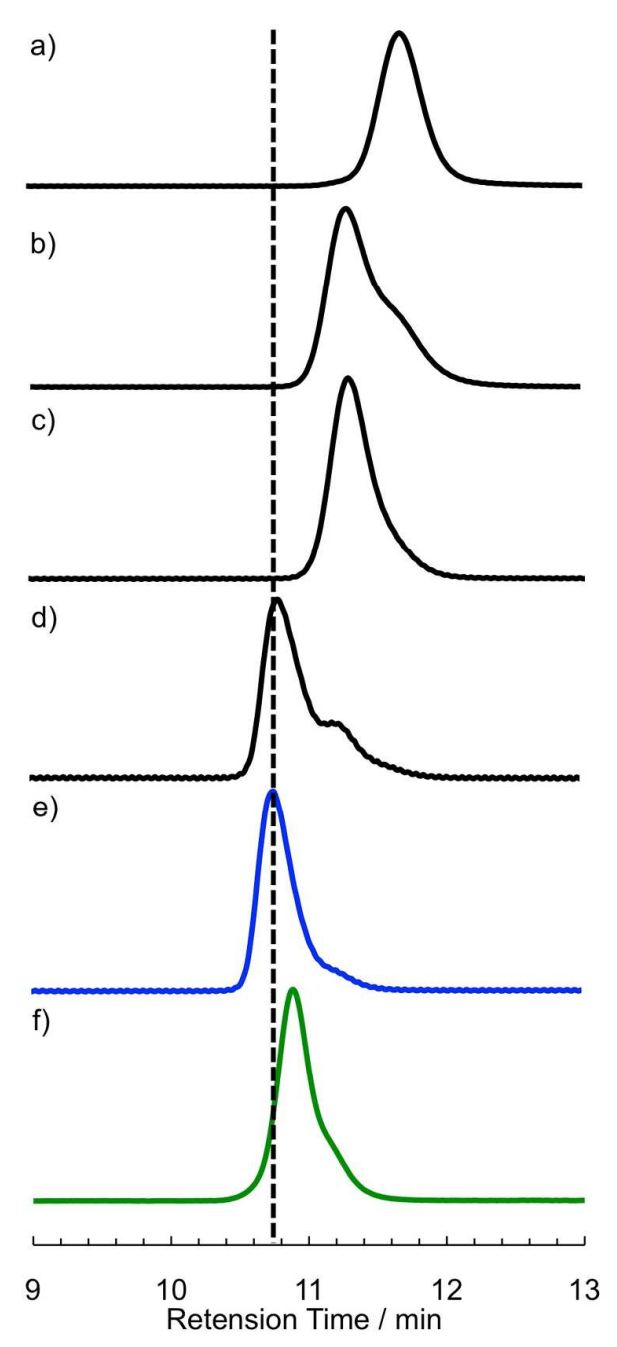

Figure S8. GPC profiles of a) chain-end diphenylethylene-functionalized polystyrene (PS-DPE), b) after addition reaction of PS-DPE and living polystyrene, c) in-chain-azide-functionalized polystyrenes (PS-(N $\left.\left.\mathrm{N}_{3}\right)-\mathrm{PS}\right)$, d) after click reaction of PS-(N3)-PS and DABBF-dialkyne, e) eight-arm star polystyrene with DABBF in the core of polymer structure (blue), and f) after treatment with a radical generator (V-70) (green). 

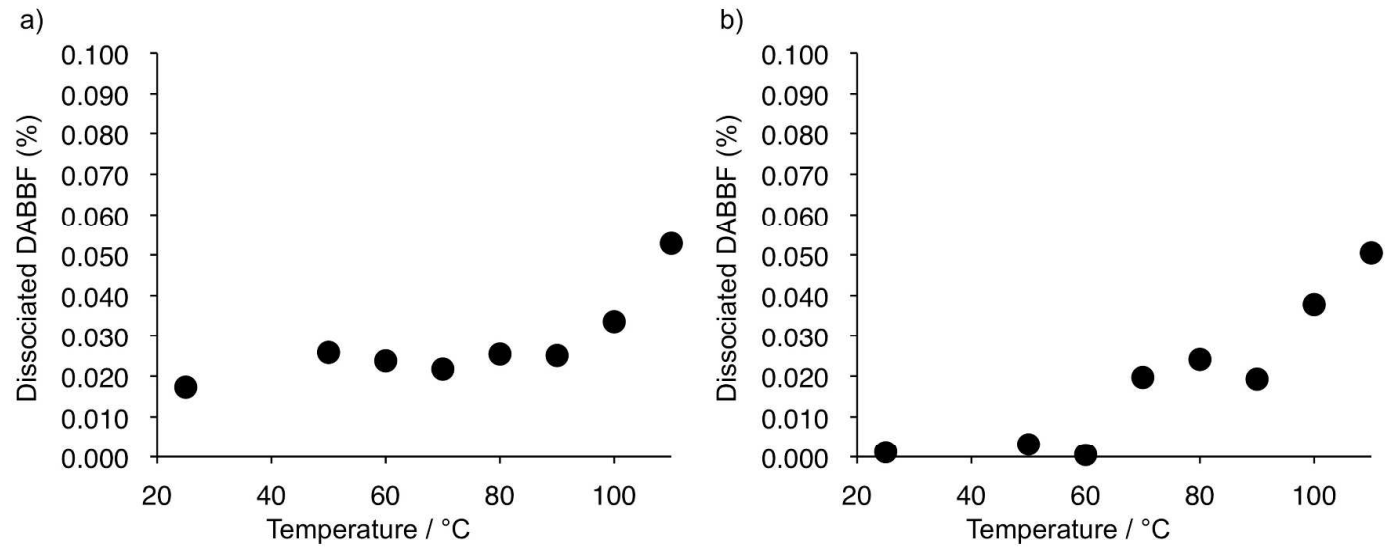

Figure S9. The ratio of dissociated DABBF in a) linear PS2 $\left(M_{\mathrm{n}}=24700 \mathrm{~g} \mathrm{~mol}^{-1}\right)$ and b) eight-arm star PS $\left(M_{\mathrm{n}}=81600 \mathrm{~g} \mathrm{~mol}^{-1}\right)$ during the heating process from 25 to $110^{\circ} \mathrm{C}$. 


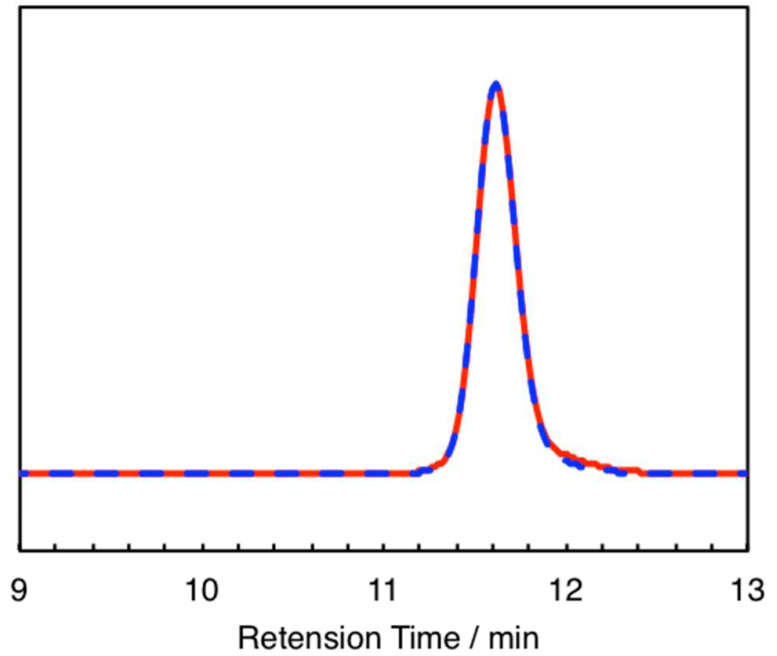

Figure S10. GPC profiles of linear polystyrene with DABBF in the center of polymer chain $\left(M_{\mathrm{n}}\right.$ $=13100)$ before (red solid) and after (blue dashed) grinding $\left(M_{\mathrm{n}}=13100\right)$. 


\section{References}

1. Imato, K.; Irie, A.; Kosuge, T.; Ohishi, T.; Nishihara, M.; Takahara, A.; Otsuka, H. Angew. Chem. Int. Ed. 2015, 54, 6168-6172.

2. Imato, K.; Nishihara, M.; Kanehara, T.; Amamoto, Y.; Takahara, A.; Otsuka, H. Angew. Chem. Int. Ed. 2012, 51, 1138-1142.

3. Earl, R. A.; Vollhardt, K. P. C. J. Org. Chem. 1984, 49, 4786-4800.

4. Höcker, H.; Latternmann, G. Makromol. Chem. 1972, 158, 191-203.

5. Lutz, J.-F. O.; Börner, H. G.; Weichenhan, K. Macromol. Rapid Commun. 2005, 26, 514-518. 